\title{
Curb Antimicrobial Resistance: Use the Right Antibiotic First!
}

\author{
by Latika Pandey, PharmD.
}

Bacteria are an ever-present entity and are ubiquitous. It is only when they infect an unwelcoming host that they become a problem. If the host's immune system cannot eradicate these microbes, then antibiotics are relied upon to assist. Antibiotics were introduced over 3,000 years ago in the form of molds to treat mainly rashes and infected wounds [1]. It was not until the $19^{\text {th }}$ century that bacteria were classified and the discovery of substances to kill them were produced.

For years, these substances, known as antibiotics, helped to fight infections and diseases. Then, some of these infections did not resolve with the use of these antibiotics. Some of the same microbes no longer seemed to be affected by these drugs. This was the beginning of the era of antimicrobial resistance.

Today, antimicrobial resistance is a rapidly growing problem that will eventually lead to serious consequences. We have identified many technical reasons for the failure of some of our antibiotics to fight certain microbes. We have found bacterial gene mutations, antibioticinactivating enzymes, intrinsic properties, and other biochemical mechanisms that are used to help certain strains survive [2]. Above all, the overuse of earlier antibiotics, to which some bacterial strains are resistant, in empiric therapy regimens seems to be leading the way to the development of resistant mutants.

Generally, the older antibiotics have the capability of eradicating all susceptible strains in a host but leaving behind the resistant mutants. The host can now transfer the resistant mutants to other hosts and thereby, promulgating resistance. Therefore, it is important to administer an antibiotic that can eliminate both the susceptible and resistant strains of bacteria at the beginning of therapy. An example of an agent that has a low propensity to create resistant strains and also has an extended spectrum of activity is cefepime, a fourth generation cephalosporin. According to a recent multicenter study, cefepime empiric therapy for moderate to severe community acquired infections is as effective as combinations of broad spectrum antibiotics [3].
Including cefepime in empiric regimens may help to curb the development of mutant pathogens.

The idea of initiating antimicrobial therapy with an agent that also eradicates mutants is also supported by of the World Health Organization in their annual report. Dr. Brundtland wrote, "the most effective strategy against antimicrobial resistance is to get the job done right the first time... to unequivocally destroy microbes...thereby defeating resistance before it starts. The challenge is to get the right treatment to the patient, each and every time... The drugs we have today can be used to prevent the infections of today and the antimicrobial-resistant catastrophes of tomorrow. However, if the world fails to mount a more serious effort to fight infectious diseases, antimicrobial resistance will increasingly threaten to send the world back to the pre-antibiotic age..." [4]

The present concept of empiric therapy reserves antimicrobial agents that combat both susceptible and resistant strains for times when initial therapy fails. This may be too late in terms of controlling the spread of mutant strains. Therefore, using the most appropriate agents first may help fight the transfer of resistant strains from host to host.

\section{References}

1. Tipton D. What is the history of antibiotics? [resource available on world wide web] URL: http:// utut.essortment.com/whatisthehist_rgic.htm. Pagewise Inc.com, 2001.

2. Animal \& Plant Health Inspection Service of the United States. Understanding the biology of antimicrobial resistance. [resource available on the world wide web] URL: http://utut.essortment.com/whatisthehist_rgic.htm. aphis.usda.gov, 2002.

3. Rodenas E. An open-label multicenter comparative phase IIIb/IV study of cefepime versus broad spectrum antibacterial therapy in moderate and severe presumed bacterial infections. In press to be published; 8 Aug 2002.

4. World Health Organization. Press Release World Health Report 2000: Drug Resistance Threatens to Reverse Medical Progress. Geneva: WHO publication 41;12 June 2000. 